\title{
Achieving social-ecological fit through bottom-up collaborative governance: an empirical investigation
}

\author{
Angela M. Guerrero $^{1,2}$, Örjan Bodin ${ }^{3}$, Ryan R. J. Mc Allister $^{4}$ and Kerrie A. Wilson $^{1,2}$
}

\begin{abstract}
Significant benefits can arise from collaborative forms of governance that foster self-organization and flexibility. Likewise, governance systems that fit with the extent and complexity of the system under management are considered essential to our ability to solve environmental problems. However, from an empirical perspective the fundamental question of whether self-organized (bottomup) collaborative forms of governance are able to accomplish adequate fit is unresolved. We used new theory and methodological approaches underpinned by interdisciplinary network analysis to address this gap by investigating three governance challenges that relate to the problem of fit: shared management of ecological resources, management of interconnected ecological resources, and crossscale management. We first identified a set of social-ecological network configurations that represent the hypothesized ways in which collaborative arrangements can contribute to addressing these challenges. Using social and ecological data from a large-scale biodiversity conservation initiative in Australia, we empirically determined how well the observed patterns of stakeholder interactions reflect these network configurations. We found that stakeholders collaborate to manage individual parcels of native vegetation, but not for the management of interconnected parcels. In addition, our data show that the collaborative arrangements enable management across different scales (local, regional, supraregional). Our study provides empirical support for the ability of collaborative forms of governance to address the problem of fit, but also suggests that in some cases the establishment of bottom-up collaborative arrangements would likely benefit from specific guidance to facilitate the establishment of collaborations that better align with the ways ecological resources are interconnected across the landscape. In our case study region, this would improve the capacity of stakeholders to detect both the intended and unintended off-site impacts of management actions. Our approach offers an avenue for empirical evaluations of collaborative governance so that preconditions for effectiveness of environmental programs can be enhanced.
\end{abstract}

Key Words: collaborative governance; Exponential Random Graph Modeling; networks; problem of fit; scales; social-ecological fit; socialecological systems

\section{INTRODUCTION}

Collaborative forms of governance are increasingly regarded as an essential mechanism for addressing environmental problems (Berkes 2009). This prescription is embedded in the highly influential research on adaptive governance and polycentric governance (Ostrom et al. 1999, Folke et al. 2005, Armitage et al. 2009, Ostrom 2010a). This prescription is also embedded in the broad stream of social science research on collaborative governance, also referred to as network governance, where collaboration is proposed as an essential mechanism to address diverse policy challenges including those related to environmental management (e.g., Ansell and Gash 2008, Provan and Kenis 2008, Klijn et al. 2010). The stated benefits of collaborative forms of governance include better integration of knowledge systems, better utilization of distributed resources, and the enabling of critical learning processes needed to understand the complexity of the managed social-ecological systems (Ostrom 1990, Walker et al. 2004, Armitage et al. 2008, Pahl-Wostl 2009, Armitage et al. 2012). Collaborative arrangements typically benefit from a considerable amount of self-organization, where actors can decide what activities they engage with and with whom they will collaborate to implement policies and programs (Folke et al. 2005, Ostrom 2010b). Thus, although collaborative governance is often thought of as a managed process (e.g., Sørensen and Torfing 2006), it largely relies on collaborating actors actively seeking to engage in collaborative activities to collectively solve problems (Lubell 2013, Lubell et al. 2014).
Environmental problems often extend over large geographic areas and require management over extended periods of time, giving rise to complex patterns of social-ecological interdependencies (Galaz et al. 2008). It has been proposed that to manage the natural environment effectively, the governance system must fit, or align with, the characteristics of the biophysical system (Young 2002, Brown 2003, Folke et al. 2007, Galaz et al. 2008). The extent to which this does not occur is referred to as the problem of fit, which is also called institutional fit. Addressing the problem of fit will enable governance arrangements to deal with diverse constraints inherent in various spatial, temporal, and functional characteristics of the biophysical environment (e.g., Cumming et al. 2006); however, not doing so could reduce the effectiveness and efficiency of environmental management (Dallimer and Strange 2015). We use the term "social-ecological fit" to reflect the challenges associated with aligning governance systems with the characteristics of the biophysical system.

Taking the core insights from research on collaborative forms of governance and the problem of fit into account, a strong case is emerging for collaboration as a means to accomplish socialecological fit. However, an unresolved question is whether selforganized collaborative arrangements that emerge from the bottom up are able to accomplish adequate social-ecological fit, or whether accomplishing social-ecological fit requires governance arrangements that are deliberately designed and coordinated in a more top-down manner (Galaz et al. 2008). Insights from contemporary case study research are in favor of

${ }^{1}$ Australian Research Council Centre of Excellence for Environmental Decisions, University of Queensland, ${ }^{2}$ School of Biological Sciences, University of Queensland, ${ }^{3}$ Stockholm Resilience Centre, Stockholm University, ${ }^{4}$ Commonwealth Scientific and Industrial Research Organisation 
the bottom-up collaborative approach (e.g., Olsson et al. 2007), and there are compelling theoretical arguments in the discourses of adaptive governance and polycentrism that favor the link between bottom-up collaborative arrangements and the ability to achieve a good social-ecological fit (Folke et al. 2005, Ostrom $2010 a$ ). Although there is a strong theoretical foundation for the link between bottom-up collaborative arrangements and socialecological fit, detailed empirical investigations using both social and ecological data in an explicit and integrated fashion are lacking (Cumming et al. 2010, Pelosi et al. 2010).

We used an empirical, interdisciplinary, and quantitative approach to explore the potential of collaborative forms of governance in achieving social-ecological fit. Our approach combined new interdisciplinary network theory and methodological tools (Bodin and Tengo 2012, Bodin et al. 2014) with new statistical models of multilevel networks (Wang et al. 2013). Our case study drew on social and ecological data from a large-scale conservation initiative in Australia that captures the activities that stakeholders engage in, where these activities are undertaken, and with whom the stakeholders collaborate. We first hypothesized the types of social-ecological network configurations that represent the ways that collaborative forms of governance contribute to achieving social-ecological fit. We then empirically examined if and to what extent the observed stakeholder interactions reflect these network configurations.

\section{Theoretical background: social-ecological fit challenges and the potential role of collaborative governance}

\section{The problem of fit}

The ability to effectively manage environmental change is contingent on the degree to which a governance system fits, or aligns with, the characteristics of the biophysical system (Young 2002, Folke 2007). This, however, is not an easy task, particularly for global environmental problems that extend political jurisdictions (e.g., the conservation of migratory species; Runge et al. 2014) or both jurisdictions and policy sectors (e.g., ocean and water management; Sabatier 2005, Crowder et al. 2006); are characterized by uncertain and rapid cumulative changes (e.g., the management of invasive species; Hobbs 2000); and exhibit a strong interplay between social and ecological systems (e.g., landuse change; Lambin et al. 2001) and spatial and temporal scales (e.g., climate change; Wilbanks and Kates 1999). Thus, addressing these global challenges requires not only the involvement of numerous actors across large geographical scales, but also the involvement of actors across multiple scales (local, regional, supraregional) and across distinct geographic yet ecologically connected areas (Young 2002, Carlsson and Berkes 2005, Folke et al. 2005, Brondizio et al. 2009, Walker et al. 2009, Ostrom 2010a, Österblom and Bodin 2012). Their interactions can enhance the formulation, refinement, and coordination of actions that are locally implemented but have global consequence (e.g., Meek 2013, Galaz et al. 2014). However, time and resource costs are associated with establishing and maintaining collaborative arrangements. Thus, collaborative arrangements can interfere with the capacity to effectively deal with environmental problems (Lazer and Friedman 2007, Visseren-Hamakers and Glasbergen 2007, Ansell and Gash 2008, Newig and Fritsch 2009, Aswani et al. 2013, Wyborn 2015). A collaborative arrangement, therefore, cannot rest on the simplistic assumption that everyone should collaborate with everyone else (McAllister and Taylor 2015). Careful consideration of the benefits of different types of collaborative arrangements is important.

Significant progress has been made in conceptualizing the problem of social-ecological fit, and interest in the topic spans the social and natural sciences (Young 2002, Cumming et al. 2006, Folke et al. 2007, Galaz et al. 2008, Young et al. 2008, Pelosi et al. 2010, Vatn and Vedeld 2012, Epstein et al. 2015). Some studies have approached the topic from a policy and institutional perspective (e.g., Ostrom 1990, Morrison 2007, Ekstrom and Young 2009, Nagendra and Ostrom 2012, Cosens 2013); others have focused on multistakeholder governance processes (e.g., Olsson et al. 2007, Meek 2013, Wyborn 2015); and others have highlighted the problem through a managerial lens, identifying instances in which management actions are not suited to the biophysical system of interest (Hobbs et al. 1993, Saunders and Briggs 2002). Some recent studies similar to ours have taken a structural approach, focusing on the interactions between and among governance actors and elements of the biophysical system (Bergsten et al. 2014, Bodin et al. 2014, Guerrero et al. 2015, Treml et al. 2015). However, in spite of these recent attempts, very few studies on the problem of fit explicitly link theories and insights on governance approaches to the features of the system being managed using empirical data.

\section{Social-ecological fit challenges}

Problems of fit arise from challenges related to the connectedness and interdependence between ecological and social systems (Galaz et al. 2008). From a social-ecological system perspective, elements of the social system (governance systems, organizations, resource users, civil society) acting at different levels (local, regional, supraregional) interact with elements of the ecological system through a set of actions ranging from those related to land and resource use to management and conservation (Gunderson and Holling 2002, Liu et al. 2007). As the spatial and/or temporal scale of environmental problems increases, fit challenges can arise from these interactions, or lack of interaction. We introduce three types of social-ecological fit challenges adapted from Galaz et al. (2008) and the hypothesized ways in which collaborative approaches to governance could address them.

\section{Challenge 1: Shared management of ecological resources}

A social-ecological fit challenge can arise when two or more actors have an interest or stake in the same biophysical resource. Acting independently of each other's decisions can lead to overexploitation of resources or ineffective, i.e., uncoordinated, management (Ostrom 1990, Berardo 2014). This governance challenge is specifically relevant for environmental problems that extend across jurisdictions and national borders. For example, watershed management can be ineffective if management is confined to individual jurisdictions without coordination between jurisdictions (Sabatier 2005). Collaborative governance can enable comanagement of biophysical resources so that planning and implementation of management actions can be coordinated amongst multiple actors (e.g., O'Keefe and DeCelles 2013).

Challenge 2: Management of interconnected ecological resources

Social-ecological fit also relates to the interconnected nature of biophysical systems (Galaz et al. 2008). For example, a fit 
challenge arises when ecological resources are connected, e.g., parcels of vegetation on farms or along wildlife corridors such as the Yellowstone-to-Yukon wildlife corridor (Chester 2006), but management responses are applied to distinct ecological resources in isolation. When ecological resources are interdependent, adverse effects can spread beyond the domain of a managing actor. This can result in either a lack of or an inadequate response to disturbances, which can lead to the propagation of biophysical change, i.e., cascading effects, or irreversible biophysical shifts, i.e., threshold effects; an example is the rapid dispersal of invasive species and the depletion of key functional species in river systems, causing fish stock to collapse (Galaz et al. 2008). From a natural sciences perspective, the need to account for the interconnected nature of biophysical systems to inform solutions to environmental problems has long been recognized (Christensen et al. 1996, Beger et al. 2010). It is increasingly common for land management policy and on-ground programs to seek to enhance the functional connectivity of landscapes to reduce the risk for species extinctions (e.g., Saura and Pascual-Hortal 2007), address the rate of invasive species spread (e.g., Chades et al. 2011), and protect the conservation values of interdependent areas (Martin et al. 2007, Iwamura et al. 2014). Notably, interconnected, or boundaryspanning, biophysical systems have been identified as an important consideration for investigating environmental governance and the problem of fit (Galaz et al. 2008, Young et al. 2008). Through collaborative governance, the spillover effects resulting from managing one of the ecological resources can be fed back to the managing actor through sharing of information and expertise with other actors managing adjacent resources who directly experience these spillover effects. Collaborative governance can therefore increase opportunities for tightening feedback loops between actions and outcomes in the management of interconnected systems, which can help prevent or deal with abrupt threshold behavior or cascade effects and enable the internalization of systemlevel management costs and benefits.

Challenge 3: Cross-scale management to maximize spatial-scale matching

Social-ecological fit challenges can also arise from issues associated with scale. The definition of scale is contested, and interpretations differ across the social and natural sciences (Sayre 2005, Higgins et al. 2012). In this paper we focus on spatial scale and use the term "scale" to refer to the spatial dimension at which diverse ecological and management processes occur, which vary along a continuum from local to broad levels of ecological and social organization (Sayre 2005, Cash et al. 2006). Scale challenges arise because of a multitude of reasons. First, the management of environmental problems tends to be planned at diverse spatial scales, from a global scale to that of individual property, whereas actions are commonly implemented at local scales (e.g., farm paddock; Saunders and Briggs 2002). Second, biophysical systems are underpinned and affected by multiple ecological and anthropogenic processes that operate simultaneously at numerous spatial scales, from nanometers to tens of thousands of kilometers, and the dominant patterns and relationships observed depend on the spatial or temporal scale of observation (Wiens 1989, Levin 1992, Poiani et al. 2000, Saunders and Briggs 2002, Cumming et al. 2015). Scale mismatches can occur if management is applied at only one scale (Kearney et al. 2012, Cattarino et al. 2014). For example, broadscale actions implemented across extensive areas can fail to have a positive effect at a local level (e.g., Wilson 2006). Minimizing scale mismatches could be important for responding to problems such as climate change (Ostrom 2010a), controlling exotic diseases (e.g., McAllister et al. 2015), and delivering large-scale restoration efforts (e.g., Guerrero et al. 2015). Through collaborative governance, diverse actors operating at multiple scales corresponding to local, regional, and supraregional levels can generate and share the knowledge required to coordinate responses to threats across different levels and implement actions at the most appropriate scales.

\section{METHODS}

\section{Analytical framework}

A network perspective can been used to describe and analyze diverse patterns of social-ecological interactions (Janssen et al. 2006): Nodes can be used to describe actors and ecological components, and ties can be used to describe social connections, ecological connections, and social-ecological connections, e.g., because of management or resource use. Together these different types of interactions can be used to describe a social-ecological system as a social-ecological network. Bodin and Tengo (2012) propose a framework for analyzing social-ecological systems in which specific patterns of social and social-ecological interactions are characterized by particular network configurations, referred to herein as building blocks, and can be theoretically linked to specific governance challenges. Using this framework, we identified building blocks that are consistent with the hypothesized ways collaborative forms of governance can facilitate the enhancement of socialecological fit (Fig. 1). We expanded this building-block approach to include considerations of scale (Guerrero et al. 2015).

The first social-ecological fit challenge relates to the shared management, or use, of ecological resources (e.g., parcels of

Fig. 1. Conceptualizing fit challenges through a social-ecological "building block" approach.

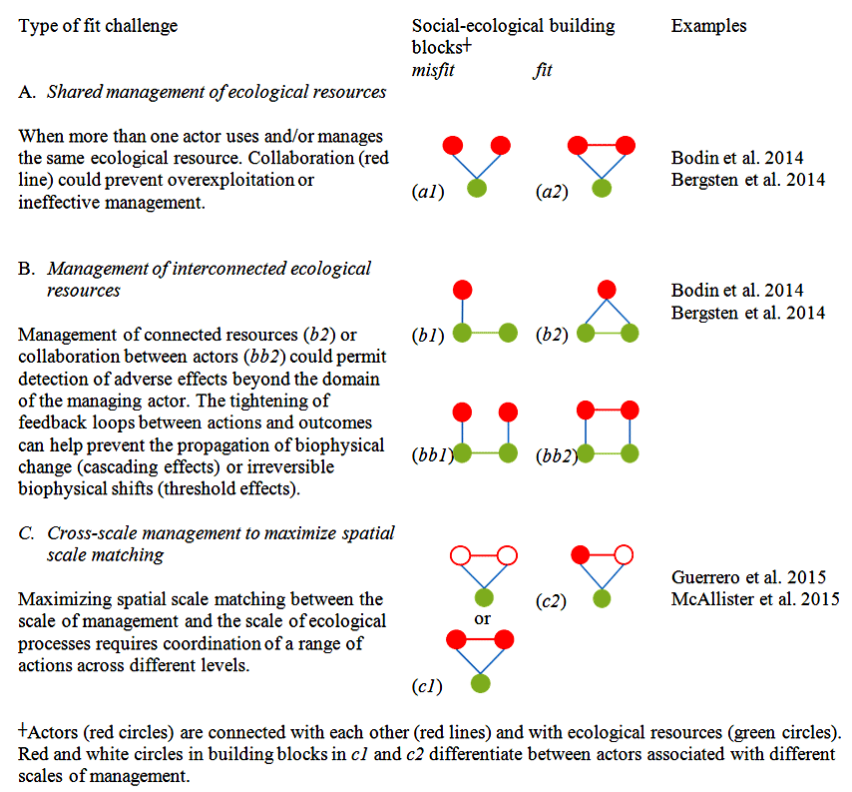

Red and white circles in building blocks in $c l$ and $c 2$ differentiate between actors associated with different scales of management. 
vegetation, catchments, species; Fig. 1A). This is illustrated by building block al (Fig. 1), where two red nodes (governance actors) are connected to the same green node (ecological resource) but are not connected to each other (i.e., they do not collaborate). The ability of a governance system to deal with this challenge is likely to increase when actors collaborate to coordinate activities, as is illustrated by building block a 2 in Figure 1.

The second social-ecological fit challenge relates to the management of interconnected ecological resources (Fig. 1B). This can occur when an actor has an interest in an ecological resource that is directly or indirectly connected with another ecological resource, or two connected ecological resources are managed independently by two different actors. This situation is illustrated by building blocks b1 and bb1 (Fig. 1), where two green nodes (ecological resources) are connected to each other, but a red node (governance actor) is only connected to one of them (b1 in Fig. 1), or the two connected green nodes (ecological resources) each have a connected red node (governance actor) but these red nodes are not connected to each other (i.e., they do not collaborate; bb1 in Fig. 1). The ability of a governance system to overcome this challenge is likely to increase when a governance actor is involved in the management of each connected ecological resource (b2 in Fig. 1). The governance ability also improves when actors managing two connected ecological resources collaborate (bb2 in Fig. 1).

The last type of social-ecological fit challenge concerns the matching between the scale of ecological processes and the scales of management (Fig. 1C). This is illustrated by building block $\mathrm{cl}$, where two red nodes (governance actors) connected to a green node (ecological resource) are associated with the same scale of management. The ability of a governance system to overcome this challenge is likely to increase when actors associated with different scales of management collaborate to coordinate actions across different levels, therefore increasing their joint ability to address key local, regional, and supraregional ecological dynamics (building block c2 in Fig. 1; Cash and Moser 2000, Young et al. 2008, Guerrero et al. 2013).

\section{Study region and data}

Our case study region, the Fitz-Stirling, is situated in Western Australia. This case study region confronts, and is an illustrative case of, several global environmental issues, including extensive deforestation, salinization, incidence of wildfire, propagation and persistence of invasive species, and the compounding and uncertain effects of climate change. The Fitz-Stirling is situated in one of the world's 34 global biodiversity hotspots, covering more than 240,000 hectares consisting mostly of private farm land (cropping and sheep grazing) with scattered parcels of vegetation, and is bounded by two of the largest areas of intact natural habitats that remain in the broader hotspot: the Fitzgerald River and the Stirling Range National Parks.

The Fitz-Stirling is part of the Gondwana Link large-scale conservation initiative, which aims to restore ecological connectivity across more than 1000 kilometers in southwestern Australia (Bradby 2013). The initiative is founded on the principles of providing venues to facilitate and support collaboration between different actors including government and nongovernment organizations. As such, the Fitz-Stirling represents a case of bottom-up collaborative governance for biodiversity conservation. It represents a unique opportunity to study a deliberately created collaborative initiative with bottomup patterns of stakeholder interaction. Thus, the results are relevant not only to the question of whether bottom-up collaborative arrangements can achieve social-ecological fit, but also to the question of whether collaborative arrangements built largely through self-organization can be deliberately created. Both these issues have substantial policy implications.

Data on the collaborative interactions between 15 actors (organizations) who undertake conservation and management activities in the Fitz-Stirling region were sourced from 25 semistructured interviews and organizations' responses to questionnaires. Actors included state and local government agencies, natural resource management groups, nongovernmental organizations, research organizations, private organizations, and community groups. Other information obtained included perceptions held by actors on the effects of collaborative relationships on the performance of on-ground activities and the geographic locations where actors perform diverse activities, including revegetation, protection of remnant vegetation, fire management, and invasive species management. Actors were coded by scale of interest as property, subregional, or supraregional level. The present analysis includes interactions across subregional and supraregional scales (see Guerrero et al., 2015 for a full description of data collection methods).

We used publicly available data on the distribution of native vegetation in the Fitz-Stirling region. More than 2000 distinct vegetation parcels, i.e., ecological resources, were identified. Our survey method required respondents to indicate on a map the vegetation parcels in which they applied their conservation and management activities. To make this feasible, the vegetation parcels were clustered based on a $0.5-\mathrm{km}$ dispersal threshold. This threshold was chosen because many bird and mammal species would experience any two parcels within a 500-meter range as well connected and therefore effectively as one coherent area of habitat, or a "metapatch" (Sutherland et al. 2000, Zetterberg et al. 2010). This resulted in 80 vegetation clusters.

\section{Characterizing and analyzing the Fitz-Stirling social-ecological network}

We characterized actors, vegetation clusters, and their interactions as a social-ecological network, where actors were the social nodes and vegetation clusters were the ecological nodes. The social connections were defined based on collaborative interactions between actors when performing key activities in the Fitz-Stirling region. These interactions included revegetation, invasive species control, livestock management, weed management, fire management, setting aside land for conservation, and land-use planning activities. The ecological connections between vegetation clusters were defined based on a species maximum dispersal threshold of $1 \mathrm{~km}$ (Fig. 2). The maximal dispersal distance corresponds to the distance that a species will not be able to, in most cases, traverse while dispersing between different habitat areas. The threshold is ultimately a species-specific measure. However, we choose a 1-km threshold because we then were able to describe the landscape's level of connectivity for a fairly broad range of species. The selected threshold is relevant for many bird species, as well as for several mammal and amphibian species (Sutherland et al. 2000, 
Zetterberg et al. 2010, Bergsten et al. 2013). However, small mammal and insect species would require smaller thresholds that better reflect their dispersal across the landscape, and larger mammals typically need larger thresholds (Sutherland et al. 2000). Interactions between the two networks, i.e., the social-ecological connections, characterize the interest that actors place on the different locations (vegetation clusters) for performing their conservation activities. The resulting Fitz-Stirling socialecological network consisted of 15 social and 80 ecological nodes and their ecological, social, and social-ecological connections.

Utilizing novel statistical network methodologies and following our analytical framework, we analyzed data describing the FitzStirling social-ecological network to test for the statistical representation of building blocks

Fig. 2. Exemplification of clusters and their connections. Vegetation patches (blue, green, and grey) were grouped into clusters (metapatches) based on an $0.5-\mathrm{km}$ distance threshold (blue, green, and grey lines). The clusters were considered ecologically connected if they were located within a distance of $1 \mathrm{~km}$ (dotted lines).

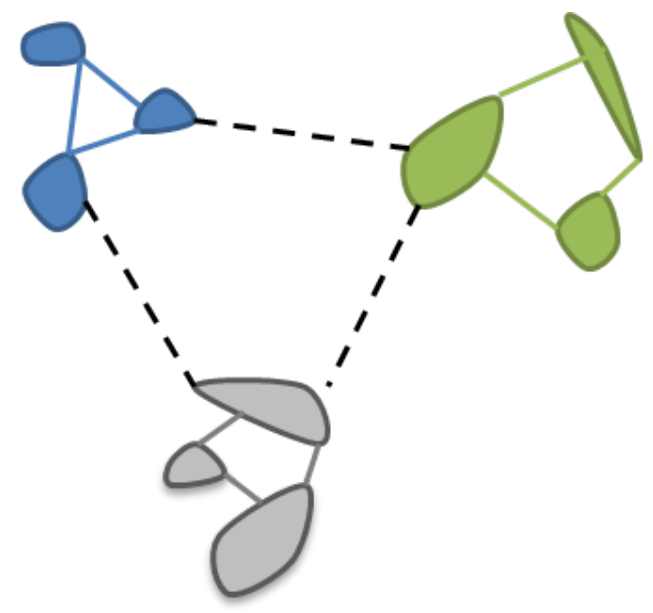

that theoretically characterize each social-ecological fit challenge. If the collaborative approach followed by the Fitz-Stirling conservation initiative has the capacity to address the fit challenges outlined in our analytical framework, we would expect building blocks a2, b2, bb2, and c2 in Figure 1 to be represented in the Fitz-Stirling network data more than would otherwise be expected by chance. For instance, for the challenge associated with the management of interconnected ecological resources, we would expect a high incidence of triangles (b2 in Fig. 1), or squares (also called 4-cycles; bb2) relative to the occurrence of other building block structures across the network.

\section{Analytical methods: Multilevel Exponential Random Graph Modeling}

We integrate our analytical framework with a methodological approach developed within the social sciences. This approach is a recent extension of a class of stochastic network models called Exponential Random Graph Models (ERGMs; Frank and Strauss 1986, Wasserman and Pattison 1996, Snijders et al. 2006). ERGMs treat the observed network as the dependent variable and can help answer questions related to which small-scale network configurations, i.e., building blocks, are more or less important in explaining the network (Lusher et al. 2012). Multilevel ERGMs (MLERGMs) account for multilevel networks in wich twolayered networks are connected through cross-level ties (Wang et al. 2013). For example, MLERGMs can be used to determine if the way ecological resources are connected influences how actors connect to each other, i.e., who they choose to collaborate with, or the way they are connected to ecological resources through cross-level ties, i.e., through management. These multilevel networks can contain multiple network configurations, e.g., different patterns of connected social and ecological nodes.

MLERGMs test the prevalence of selected configurations relative to the distribution of all other configurations in the network and account for nested configurations, i.e., when a configuration contains one or several other configurations. In this way the MLERGM approach facilitates more precise interpretations of an observed configuration than approaches that assume independence of configuration observations. Unlike other network analysis approaches, MLERGMs simultaneously evaluate a large set of network configurations to determine a selected (modeled) set of configurations' relative importance in explaining the structure of a social-ecological network. The sign of a statistically significant parameter value indicates the propensity for the associated configuration to be present in the network. In this way MLERGMs build on an analytical approach in which the researcher can test whether some specific, theoretically relevant configurations can explain the observed structure of the whole network. This feature makes it an ideal analytical tool for testing hypotheses about the processes, expressed as specific configurations (building blocks) that gave rise to the observed network. In addition to network configurations, attributes of the nodes (ecological resources or actors) can be included in the analysis to establish whether they have significant structural effects. For instance, whether a particular attribute of an actor (e.g., a particular scale of management) influences the way the actor connects to ecological resources (e.g., through the types of management decisions) can be tested.

The integration of this advanced statistical network methodology with the building-block approach to analyzing social-ecological systems was recently proposed by (Bodin et al. 2014). Through the Fitz-Stirling case study, we further elaborate and provide the first application of this novel research approach for the analysis of a collaborative initiative's ability to accomplish socialecological fit. Although current stages of software development prevented us from including all configurations from our analytical framework in our MLERGM model (building block c1 in Fig. 1), we demonstrate how the theoretical basis provided by the socialecological building-block approach can guide interpretation of the outputs of MLERGMs, and how this interpretation can lead to valuable insights on how the structure of collaborative governance arrangements can be improved so as to increase their level of social-ecological fit.

\section{RESULTS}

We fitted a MLERGM model to data describing the Fitz-Stirling social-ecological network that included the 11 configurations shown in Figure 3. Six of these configurations (a-f) are baseline 
configurations that help explain the overall social-ecological network structure. These configurations are critical for providing a baseline for the configurations of interest, namely, those that suggest social-ecological fit (configurations g-k in Fig. 3). The parameter estimate for configuration $\mathrm{c}$ is significant and negative in the MLERGM. This suggests that the Fitz-Stirling socialecological network contains fewer of these configurations than would otherwise be expected by chance, implying that actors do not give preference to a location already being managed by other actor(s). The significant and positive parameter estimate for configuration d suggests that some actors tend to undertake their activities in many different locations compared with an average actor. Likewise, configuration $\mathrm{e}$ is significantly positive, suggesting that locations chosen by actors tend to be connected with other locations. In contrast, a significant and negative parameter estimate for configuration $\mathrm{f}$ suggests that actors do not tend to collaborate with other actors working in a location different from their own.

Fig. 3. Multilevel Exponential Random Graph Model for the Fitz-Stirling social-ecological network. Estimated parameter and observed configuration counts are based on a model with a fixed ecological network component. This reflects our interest in testing whether connections between ecological resources are associated with the locations chosen by actors (the socialecological connection) and with whom they chose to collaborate (the connection between actors).

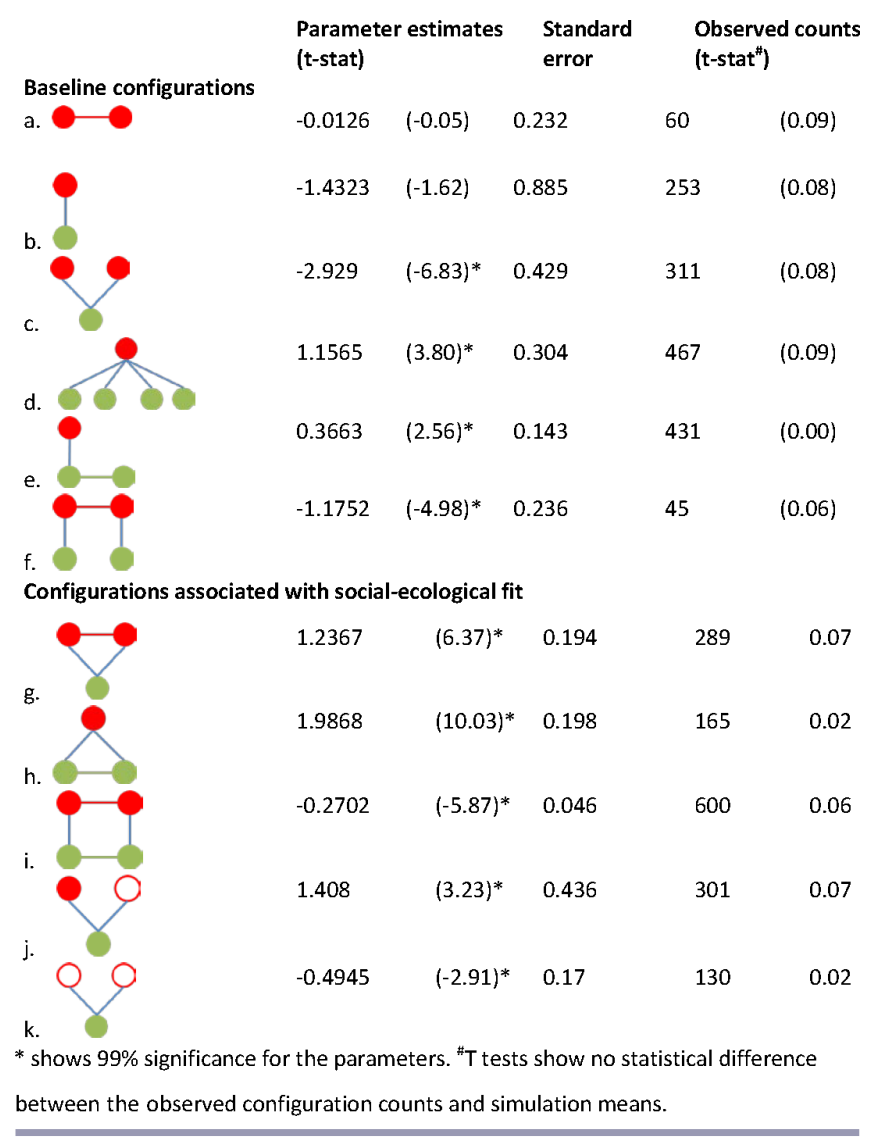

The remaining configurations in Figure 3 relate to socialecological fit and reflect the social-ecological building blocks described in our conceptual framework (Fig. 1). However, a key feature of the MLERGM method is that interpretation of results can be enhanced by simultaneously considering results of configurations that are nested within others. Thus, our interpretations of the configurations that relate to socialecological fit also considered the results for some of the baseline configurations already discussed.

Configuration g relates to the fit challenge of shared management of ecological resources. The parameter estimate for this configuration is significant and positive. Interpretation of this result can be enhanced by simultaneously considering the parameter estimate for baseline configuration $\mathrm{c}$. This is because configuration $\mathrm{c}$ is nested within configuration $\mathrm{g}$. The consideration of parameter estimates for configurations $\mathrm{c}$ and $\mathrm{g}$ suggests that even though two actors do not tend to work in the same location (given the negative parameter estimate for baseline configuration c), when they do work in the same location, i.e., the same ecological resource, they tend to collaborate (given the positive parameter estimate of configuration $\mathrm{g}$ ).

Configurations $\mathrm{h}$ and $\mathrm{i}$ relate to the fit challenge of the management of interconnected ecological resources. The result for configuration $\mathrm{h}$ considered together with the result for baseline configuration e suggests that actors tend to work in a location that is connected to another location (given the significant and positive parameter estimate for configuration e) and that they have a strong propensity toward working in these other locations as well (given the significant and positive parameter estimate for configuration h). Configuration i depicts situations where two actors each manage two different, yet connected, ecological resources. The parameter for this configuration was significant and negative, suggesting that there are fewer of these configurations in the Fitz-Stirling social-ecological network data than would otherwise be expected by chance. This result considered together with the result for baseline configuration $f$ implies that actors do not tend to collaborate with others working in different locations (given the parameter estimate of baseline configuration $\mathrm{f}$ ) and are even less likely to do so when these locations are connected (given the parameter estimate for configuration i). From a governance perspective a negative parameter for configuration $\mathrm{f}$ can be seen as desirable, because spending time collaborating with other actors whose locations are not the same as your own is potentially inefficient. However, this result is less desirable when considering the result for configuration i, because when the locations are connected, collaboration between actors could improve the coordination of management activities, e.g., invasive species management, revegetation of areas to facilitate wildlife movement.

The last two configurations depict situations where locations are being managed at one scale (configuration $\mathrm{k}$ ) or at different scales (configuration j). The negative and significant parameter estimate for configuration $\mathrm{k}$ suggests that actors managing at the same scale tend to avoid managing the same locations, over and above the general avoidance of sharing locations as observed with configuration c. Conversely, the positive and significant parameter estimate for configuration $\mathrm{j}$ suggests that actors managing at different scales tend to manage the same locations, 
although the general tendency to avoid sharing locations still applies. These results imply that even though actors tend to avoid locations managed by others, this tendency is reduced if the other actor is managing at a different scale. Unfortunately, because of methodological constraints we were not able to test whether the actors managing at different scales tended to collaborate or not (Fig. 1, configuration c); however, the general tendency to collaborate with actors sharing a resource still applies (Fig. 3, configuration g).

Results regarding the perceptions of Fitz-Stirling actors' on their collaborative relationships can be found in Appendix 1. This information was used to aid interpretation of the MLERGM results.

\section{DISCUSSION}

We integrated social and ecological data to evaluate the capacity for a conservation initiative to address three governance challenges related to the problem of fit: (1) shared management of ecological resources, (2) the management of interconnected ecological resources to avoid thresholds being exceeded and cascading effects, and (3) cross-scale management to maximize spatial scale mismatching. We found that the collaborative approach of the Fitz-Stirling conservation initiative is able to deal with some but not all of the governance challenges related to the problem of fit described in Figure 1. For instance, there is a tendency for collaboration when actors manage the same parcels of vegetation, but not when managing interconnected parcels of vegetation. This indicates that the initiative can enable the coordination of diverse management actions for particular locations, i.e., shared management of ecological resources, but may not support coordinated management actions across different locations, i.e., management of interconnected ecological resources. This result is supported by data on the perceptions held by Fitz-Stirling actors about the effects of collaborative relationships on the performance of on-ground activities. For example, $83 \%$ of collaborations were perceived as delivering some results, very good results, or results above expectations for the particular activity performed at particular locations (Appendix 1, Fig. A1.1). In contrast, insufficient communication and coordination were highlighted as an important barrier to successfully carrying out conservation activities across the region (Appendix 1, Fig. A1.2). Qualitative data captured through indepth interviews suggest that this is especially a problem when diverse management actions need to be coordinated to reduce undesirable feedback loops between activities. For example, fire management strategies can negatively affect revegetation outcomes when they do not consider revegetation activities being carried out in nearby locations. Likewise, revegetation plans that ignore fire management plans can reduce the effectiveness of fire management activities across locations.

Although we were unable to test the particular social-ecological network configuration directly associated with scale mismatch challenges (i.e., whether actors managing at different scales tended to collaborate or not; Fig. 1C), we found that actors operating at different scales tended to share locations. We also found that when actors share a location, in general they tend to collaborate. Together these results suggest that the Fitz-Stirling conservation initiative is promoting cross-scale collaborative management. This finding is demonstrated by the invasive species management activities undertaken as part of the Red Card for Rabbits and Foxes program, which have involved diverse stakeholders from regional coordinators to local landholders (Tulloch et al. 2014). Furthermore, a previous study of the Fitz-Stirling conservation initiative found evidence indicating cross-scale management (Guerrero et al. 2015). However, in that study the ecological system was not considered and an assessment of cross-scale management was limited to the governance system. By considering social-ecological interdependencies, we were able to assess how the governance structure aligns to the ecological system and whether connections between ecological resources influence collaboration between actors at different scales of management.

By linking the results from the quantitative social-ecological network analysis with qualitative data gathered through interviews, we provide tentative support for our hypothesized relationships between the level of fit (between the observed structure of collaborative relationships and the structure of the ecological system) and governance capacity to deal with the associated fit challenges (Fig. 1). We conclude that the collaborative approach of the Fitz-Stirling conservation initiative shows the capacity to deal with the fit challenges associated with the shared management of ecological resources; however, it lacks the capacity to detect the effects of management actions that are applied in particular locations but that affect outcomes at connected locations. The ability to deal with this challenge would likely be enhanced by improving collaboration among actors working in connected locations (Fig. 1, building block bb2). This would allow increased opportunities for detection of feedback loops between actions and outcomes, thereby increasing the likelihood that the governance system could respond to the effects of adverse actions occurring beyond the ecological resource being managed to avoid exceeding thresholds and to minimize cascading effects. We do not claim that achieving alignment between collaborative patterns of interactions and the structures of the managed biophysical systems guarantees effective management, but that such an alignment is a precondition to effective management.

Overall, results of this empirical research support the idea that certain level of coordination of self-organizing collaborative arrangements might be necessary to create governance systems able to deal with the problem of fit. Our framework capture three of the four types of misfits identified by Galaz et al. (2008), but could be expanded to classify, capture, and explicitly define a greater diversity of fit challenges in social-ecological network terms. For example, diverse social-ecological network configurations can be used to theorize when a governance arrangement is better structured to address temporal mismatch challenges (Cumming et al. 2006, Galaz et al. 2008). Temporal dimensions could be captured by assigning them as attributes to the social and ecological components of networks, i.e., nodes. Doing so would provide a theoretical basis for future testing and facilitate future systematic research on temporal dimensions of the problem of fit (Munck af Rosenschöld et al. 2014). In addition, the Exponential Random Graph Modeling software used in this analysis is limited to a subset of social-ecological network configurations. The incorporation of more elaborate social-ecological configurations would allow fit challenges to be captured in a more comprehensive way. For example, the effects 
of a threat occurring at a particular scale could be significantly different from the effects of the same threat occurring at a different scale (e.g., the effects of broad-scale versus localized grazing on habitat connectivity; Cattarino et al. 2014). To analyze such issues, researchers require configurations that describe different governance levels and the connections between different management and ecological scales. Ongoing development of analytical approaches is needed so that a wide diversity of fit challenges can be explored. The results of such analyses can then provide an evidence base for developing management recommendations to address this fit challenge.

Our approach can be replicated and applied in different contexts; thus, similar studies in other areas and contexts are possible. In addition, combining this approach with qualitative assessments of the governance process can elucidate how other factors can affect the effectiveness of collaborative forms of governance. Examples are assessments of the effect of costs and barriers to collaboration on the ability to align governance structures to ecological systems (e.g., Wyborn 2015), and factors such as the quality of relationships (Lauber et al. 2011), the qualities of key individuals (Harrington et al. 2006, Keys et al. 2009, Shackleton et al. 2009), and other aspects such as power imbalances and trust issues (Adger et al. 2005, Hahn et al. 2006) that affect the effectiveness of diverse governance arrangements. Although our results are based on defensible assumptions such as the distance thresholds used to define ecological connectivity, the results are sensitive to the assumption specifics. Nevertheless, our analysis supports transparent discussion on an important applied issue and allows us to thoroughly present and further develop innovative approaches for studying problems of fit.

\section{CONCLUSION}

Although the concept of social-ecological fit is quite well developed, empirical research on the capacity for collaborative governance arrangements to address the problem of fit is in its infancy. We expanded a recently proposed framework (Bodin and Tengo 2012) and used social and ecological data to theorize specific social-ecological fit challenges related to the management of social-ecological systems. We empirically tested whether a large-scale collaborative conservation initiative in Australia has the propensity to address these challenges. We demonstrated the applicability of our approach through an assessment of the degree to which the studied governance system fits, or aligns with, the characteristics of the biophysical system. Our findings suggest that the observed collaborative arrangements are able to address many challenges associated with social-ecological fit. In particular, actors are able to configure themselves in various collaborative arrangements that adhere to basic principles for achieving social-ecological fit. They are largely able to establish collaborations with other actors with whom they share specific ecological resources (here, distinguishable parcels of vegetation in a landscape), and they are able to collaborate with other actors operating on a different scale of management. Furthermore, they tend to work with ecological resources that are ecologically interconnected, thereby tightening the feedback loop between management activities and their consequences on a broader ecological scale. They are, however, less able to establish collaborations that align with the connectivity between different ecological resources.
Our results suggest that the establishment of bottom-up collaborative arrangements would likely benefit from some degree of top-down management, to guide and facilitate the establishment of collaborations that better align with the different constraints inherent in the biophysical characteristics of the managed ecosystems (cf., network management, e.g., Klijn et al. 2010). These findings resonate with the "networks of networks" proposition of Galaz et al. (2008). They propose that selforganized networks might need to be temporally steered and coordinated to cope with nonlinear behavior of biophysical systems. The basic premise is that this would be beneficial when the effects of social and ecological processes propagate across scales extending beyond the problem-solving capacity of selforganized networks. For our study region, the promotion of collaboration between actors working in ecologically connected areas would likely improve the effectiveness of on-ground management actions.

Our research provides unique cross-disciplinary empirical evidence of the role of bottom-up collaborative approaches to governance for addressing the problem of fit. By providing a detailed analysis of the intricate and complex web of interdependencies between social and ecological systems, we show the potential value and shortcomings of self-organized collaborative arrangements. In this way we have contributed to bridging the significant gap between the rapidly developed and largely theoretical claims about how different collaborative arrangements are able to address environmental challenges and the cross-disciplinary empirical foundations upon which many of these claims ultimately rest. Finally, the approach used and results derived from our study offer great potential for designing and evaluating the structure of collaborative arrangements so that preconditions for effectiveness of environmental programs can be improved.

Responses to this article can be read online at: http://www.ecologyandsociety.org/issues/responses. $\mathrm{php} / 8035$

\begin{abstract}
Acknowledgments:
We are grateful for the land managers and organizations that participated in the research study. We are also thankful for feedback on the manuscript and survey instrument from A. Tulloch, $J$. Corcoran, J. Hayllar, and E. Law, and for analytical support from H. Beyer. We acknowledge the Australian Government's National Environmental Research Program, the Australian Research Council Centre of Excellence for Environmental Decisions and the Australian Research Council Linkage Programs, and CSIR's Land and Water flagship for funding and support. KAW was supported by an Australian Research Council Future Fellowship, and ÖB was supported through MISTRA and the strategic research program Ekoklim at Stockholm University.
\end{abstract}

\section{LITERATURE CITED}

Adger, W. N., K. Brown, and E. L. Tompkins. 2005. The political economy of cross-scale networks in resource co-management. Ecology and Society 10(2):9. [online] URL: http://www. ecologyandsociety.org/vol10/iss2/art9/ 
Ansell, C., and A. Gash. 2008. Collaborative governance in theory and practice. Journal of Public Administration Research and Theory 18:543-571. http://dx.doi.org/10.1093/jopart/mum032

Armitage, D., R. de Loë, and R. Plummer. 2012. Environmental governance and its implications for conservation practice. Conservation Letters 5:245-255. http://dx.doi.org/10.1111/ j.1755-263X.2012.00238.X

Armitage, D., M. Marschke, and R. Plummer. 2008. Adaptive comanagement and the paradox of learning. Global Environmental Change 18:86-98. http://dx.doi.org/10.1016/j.gloenvcha.2007.07.002

Armitage, D. R., R. Plummer, F. Berkes, R. I. Arthur, A. T. Charles, I. J. Davidson-Hunt, A. P. Diduck, N. C. Doubleday, D. S. Johnson, M. Marschke, P. McConney, E. W. Pinkerton, and E. K. Wollenberg. 2009. Adaptive co-management for socialecological complexity. Frontiers in Ecology and the Environment 7:95-102. http://dx.doi.org/10.1890/070089

Aswani, S., G. G. Gurney, S. Mulville, J. Matera, and M. Gurven. 2013. Insights from experimental economics on local cooperation in a small-scale fishery management system. Global Environmental Change 23:1402-1409. http://dx.doi.org/10.1016/j. gloenvcha.2013.08.003

Beger, M., H. S. Grantham, R. L. Pressey, K. A. Wilson, E. L. Peterson, D. Dorfman, P. J. Mumby, R. Lourival, D. R. Brumbaugh, and H. P. Possingham. 2010. Conservation planning for connectivity across marine, freshwater, and terrestrial realms. Biological Conservation 143:565-575. http://dx.doi.org/10.1016/j. biocon.2009.11.006

Berardo, R. 2014. Bridging and bonding capital in two-mode collaboration networks. Policy Studies Journal 42(2):197-225. $\underline{\text { http://dx.doi.org/10.1111/psj.12056 }}$

Bergsten, A., Ö. Bodin, and F. Ecke. 2013. Protected areas in a landscape dominated by logging - a connectivity analysis that integrates varying protection levels with competitioncolonization tradeoffs. Biological Conservation 160:279-288. http://dx.doi.org/10.1016/j.biocon.2013.01.016

Bergsten, A., D. Galafassi, and Ö. Bodin. 2014. The problem of spatial fit in social-ecological systems: detecting mismatches between ecological connectivity and land management in an urban region. Ecology and Society 19(4):6. http://dx.doi. org/10.5751/ES-06931-190406

Berkes, F. 2009. Evolution of co-management: role of knowledge generation, bridging organizations and social learning. Journal of Environmental Management 90:1692-1702. http://dx.doi.org/10.1016/ j.jenvman.2008.12.001

Bodin, Ö., B. Crona, M. Thyresson, A.-L. Golz, and M. Tengo. 2014. Conservation success as a function of good alignment of social and ecological structures and processes. Conservation Biology 28:1371-1379. http://dx.doi.org/10.1111/cobi.12306

Bodin, Ö., and M. Tengo. 2012. Disentangling intangible socialecological systems. Global Environmental Change 22:430-439. http://dx.doi.org/10.1016/j.gloenvcha.2012.01.005

Bradby, K. 2013. Gondwana Link: 1000 kilometres of hope. Pages 25-35 in J. Fitzsimons, I. Pulsford, and G. Wescott, editors. Linking Australia's landscapes: lessons and opportunities from large-scale conservation networks. CSIRO Publishing, Collingwood, Australia.

Brondizio, E. S., E. Ostrom, and O. R. Young. 2009. Connectivity and the governance of multilevel social-ecological systems: the role of social capital. Annual Review of Environment and Resources 34:253-278. http://dx.doi.org/10.1146/annurev. environ.020708.100707

Brown, K. 2003. Integrating conservation and development: a case of institutional misfit. Frontiers in Ecology and the Environment 1(9): 479-487. http://dx.doi.org/10.1890/1540-9295 (2003)001[0479:ICADAC]2.0.CO;2

Carlsson, L., and F. Berkes. 2005. Co-management: concepts and methodological implications. Journal of Environmental Management 75:65-76. http://dx.doi.org/10.1016/j.jenvman.2004.11.008

Cash, D. W., W. N. Adger, F. Berkes, P. Garden, L. Lebel, P. Olsson, L. Pritchard, and O. Young. 2006. Scale and cross-scale dynamics: governance and information in a multilevel world. Ecology and Society 11(2):8. [online] URL: http://www.ecologyandsociety. org/vol11/iss2/art8/

Cash, D. W., and S. C. Moser. 2000. Linking global and local scales: designing dynamic assessment and management processes. Global Environmental Change 10:109-120. http://dx.doi. org/10.1016/s0959-3780(00)00017-0

Cattarino, L., C. A. McAlpine, and J. R. Rhodes. 2014. Land-use drivers of forest fragmentation vary with spatial scale. Global Ecology and Biogeography 23:1215-1224. http://dx.doi.org/10.1111/ geb. 12187

Chades, I., T. G. Martin, S. Nicol, M. A. Burgman, H. P. Possingham, and Y. M. Buckley. 2011. General rules for managing and surveying networks of pests, diseases, and endangered species. Proceedings of the National Academy of Sciences of the United States of America 108:8323-8328. http://dx.doi. org/10.1073/pnas.1016846108

Chester, C. C. 2006. Conservation across borders: biodiversity in an interdependent world. Island Press, Washington, D.C., USA.

Christensen, N. L., A. M. Bartuska, J. H. Brown, S. Carpenter, C. D'Antonio, R. Francis, J. F. Franklin, J. A. MacMahon, R. F. Noss, D. J. Parsons, C. H. Peterson, M. G. Turner, and R. G. Woodmansee. 1996. The report of the Ecological Society of America Committee on the scientific basis for ecosystem management. Ecological Applications 6:665-691. http://dx.doi. org/10.2307/2269460

Cosens, B. A. 2013. Legitimacy, adaptation, and resilience in ecosystem management. Ecology and Society 18(1):3. http://dx. doi.org/10.5751/ES-05093-180103

Crowder, L. B., G. Osherenko, O. R. Young, S. Airame, E. A. Norse, N. Baron, J. C. Day, F. Douvere, C. N. Ehler, B. S. Halpern, S. J. Langdon, K. L. McLeod, J. C. Ogden, R. E. Peach, A. A. Rosenberg, and J. A. Wilson. 2006. Resolving mismatches in US ocean governance. Science 313:617-618. http://dx.doi.org/10.1126/ science. 1129706

Cumming, G. S., C. R. Allen, N. C. Ban, D. Biggs, H. C. Biggs, D. H. M. Cumming, A. De Vos, G. Epstein, M. Etienne, K. Maciejewski, R. Mathevet, C. Moore, M. Nenadovic, and M. 
Schoon. 2015. Understanding protected area resilience: a multiscale, social-ecological approach. Ecological Applications 25:299-319. http://dx.doi.org/10.1890/13-2113.1

Cumming, G. S., Ö. Bodin, H. Ernstson, and T. Elmqvist. 2010. Network analysis in conservation biogeography: challenges and opportunities. Diversity and Distributions 16:414-425. http://dx. doi.org/10.1111/j.1472-4642.2010.00651.x

Cumming, G. S., D. H. M. Cumming, and C. L. Redman. 2006. Scale mismatches in social-ecological systems: causes, consequences, and solutions. Ecology and Society 11(1):14. [online] URL: http://www.ecologyandsociety.org/vol11/iss1/ $\underline{\operatorname{art14/}}$

Dallimer, M., and N. Strange. 2015. Why socio-political borders and boundaries matter in conservation. Trends in Ecology \& Evolution 30:132-139. http://dx.doi.org/10.1016/j.tree.2014.12.004

Ekstrom, J. A., and O. R. Young. 2009. Evaluating functional fit between a set of institutions and an ecosystem. Ecology and Society 14(2):16. [online] URL: http://www.ecologyandsociety. org/vol14/iss2/art16/

Epstein, G., J. Pittman, S. M. Alexander, S. Berdej, T. Dyck, U. Kreitmair, K. J. Raithwell, S. Villamayor-Tomas, J. Vogt, and D. Armitage. 2015. Institutional fit and the sustainability of socialecological systems. Current Opinion in Environmental Sustainability 14:34-40. http://dx.doi.org/10.1016/j.cosust.2015.03.005

Folke, C., T. Hahn, P. Olsson, and J. Norberg. 2005. Adaptive governance of social-ecological systems. Annual Review of Environment and Resources 30:441-473. http://dx.doi.org/10.1146/ annurev.energy.30.050504.144511

Folke, C., L. Pritchard, F. Berkes, J. Colding, and U. Svedin. 2007. The problem of fit between ecosystems and institutions: ten years later. Ecology and Society 12(1):30. [online] URL: http://www. ecologyandsociety.org/vol12/iss1/art30/

Frank, O., and D. Strauss. 1986. Markov graphs. Journal of the American Statistical Association 81:832-842. http://dx.doi. org/10.1080/01621459.1986.10478342

Galaz, V., P. Olsson, T. Hahn, and U. Svedin. 2008. The problem of fit among biophysical systems, environmental and resource regimes, and broader governance systems: insights and emerging challenges. Pages 147-186 in O. Young, L. A. King, and H. Schroeder, editors. Institutions and environmental change: principal findings, applications, and research frontiers. MIT Press, Cambridge, Massachusetts, USA.

Galaz, V., H. Österblom, Ö. Bodin, and B. Crona. 2014. Global networks and global change-induced tipping points. International Environmental Agreements: Politics, Law and Economics 1-33. http://dx.doi.org/10.1007/s10784-014-9253-6

Guerrero, A. M., R. R. J. McAllister, J. Corcoran, and K. A. Wilson. 2013. Scale mismatches, conservation planning, and the value of social-network analyses. Conservation Biology 27:35-44. http://dx.doi.org/10.1111/j.1523-1739.2012.01964.x

Guerrero, A. M., R. R. J. McAllister, and K. A. Wilson. 2015. Achieving cross-scale collaboration for large scale conservation initiatives. Conservation Letters 8:107-117. http://dx.doi. org/10.1111/conl.12112
Gunderson, L. H., and C. S. Holling. 2002. Panarchy: understanding transformations in human and natural systems. Island Press, Washington, D.C., USA.

Hahn, T., P. Olsson, C. Folke, and K. Johansson. 2006. Trustbuilding, knowledge generation and organizational innovations: the role of a bridging organization for adaptive comanagement of a wetland landscape around Kristianstad, Sweden. Human Ecology 34:573-592. http://dx.doi.org/10.1007/s10745-006-9035$\underline{Z}$

Harrington, C., R. Lane, and D. Mercer. 2006. Learning conservation: the role of conservation covenants in landscape redesign at Project Hindmarsh, Victoria. Australian Geographer 37:187-209. http://dx.doi.org/10.1080/00049180600672342

Higgins, S., M. Mahon, and J. McDonagh. 2012. Interdisciplinary interpretations and applications of the concept of scale in landscape research. Journal of Environmental Management 113:137-145. http://dx.doi.org/10.1016/j.jenvman.2012.08.027

Hobbs, R. J. 2000. Invasive species in a changing world. Island Press, Washington, D.C., USA.

Hobbs, R. J., D. A. Saunders, and G. W. Arnold. 1993. Integrated landscape ecology: a Western Australian perspective. Biological Conservation 64:231-238. http://dx.doi.org/10.1016/0006-3207 (93)90324-T

Iwamura, T., R. A. Fuller, and H. P. Possingham. 2014. Optimal management of a multispecies shorebird flyway under sea-level rise. Conservation Biology 28:1710-1720. http://dx.doi.org/10.1111/ cobi.12319

Janssen, M. A., Ö. Bodin, J. M. Anderies, T. Elmqvist, H. Ernstson, R. R. J. McAllister, P. Olsson, and P. Ryan. 2006. Toward a network perspective of the study of resilience in socialecological systems. Ecology and Society 11(1):15. [online] URL: http://www.ecologyandsociety.org/vol11/iss1/art15/

Kearney, F., R. R. J. McAllister, and N. D. MacLeod. 2012. Conservation and grazing in Australia's north-east: the bridled nailtail wallaby. Pastoralism: Research, Policy and Practice 2:20. http://dx.doi.org/10.1186/2041-7136-2-20

Keys, N., D. Thomsen, and T. F. Smith. 2009. Opinion leaders and complex sustainability issues. Management of Environmental Quality: An International Journal 21:187-197.

Klijn, E.-H., B. Steijn, and J. Edelenbos. 2010. The impact of network management on outcomes in governance networks. Public Administration 88:1063-1082. http://dx.doi.org/10.1111/ j.1467-9299.2010.01826.X

Lambin, E. F., B. L. Turner, H. J. Geist, S. B. Agbola, A. Angelsen, J. W. Bruce, O. T. Coomes, R. Dirzo, G. Fischer, C. Folke, P. S. George, K. Homewood, J. Imbernon, R. Leemans, X. Li, E. F. Moran, M. Mortimore, P. S. Ramakrishnan, J. F. Richards, H. Skaånes, W. Steffen, G. D. Stone, U. Svedin, T. A. Veldkamp, C. Vogel, and J. Xu. 2001. The causes of land-use and land-cover change: moving beyond the myths. Global Environmental Change 11:261-269. http://dx.doi.org/10.1016/s0959-3780(01)00007-3

Lauber, T. B., R. C. Stedman, D. J. Decker, B. A. Knuth, and C. N. Simon. 2011. Social network dynamics in collaborative conservation. Human Dimensions of Wildlife 16:259-272. http:// dx.doi.org/10.1080/10871209.2011.542556 
Lazer, D., and A. Friedman. 2007. The network structure of exploration and exploitation. Administrative Science Quarterly 52:667-694. http://dx.doi.org/10.2189/asqu.52.4.667

Levin, S. A. 1992. The problem of pattern and scale in ecology: the Robert H. MacArthur Award Lecture. Ecology 73:1943-1967. http://dx.doi.org/10.2307/1941447

Liu, J. G., T. Dietz, S. R. Carpenter, M. Alberti, C. Folke, E. Moran, A. N. Pell, P. Deadman, T. Kratz, J. Lubchenco, E. Ostrom, Z. Ouyang, W. Provencher, C. L. Redman, S. H. Schneider, and W. W. Taylor. 2007. Complexity of coupled human and natural systems. Science 317:1513-1516. http://dx.doi. org/10.1126/science. 1144004

Lubell, M. 2013. Governing institutional complexity: the ecology of games framework. Policy Studies Journal 41:537-559. http:// dx.doi.org/10.1111/psj.12028

Lubell, M., G. Robins, and P. Wang. 2014. Network structure and institutional complexity in an ecology of water management games. Ecology and Society 19(4):23. http://dx.doi.org/10.5751/ ES-06880-190423

Lusher, D., J. Koskinen, and G. Robins, editors. 2012. Exponential random graph models for social networks. Cambridge University Press, Cambridge, UK. http://dx.doi.org/10.1017/cbo9780511894701

Martin, T. G., I. Chadès, P. Arcese, P. P. Marra, H. P. Possingham, and D. R. Norris. 2007. Optimal conservation of migratory species. PLoS ONE 2:e751. http://dx.doi.org/10.1371/journal. pone. 0000751

McAllister, R. R. J., C. J. Robinson, K. Maclean, A. M. Guerrero, K. Collins, B. M. Taylor, and P. J. De Barro. 2015. From local to central: a network analysis of who manages plant pest and disease outbreaks across scales. Ecology and Society 20(1):67. http://dx. doi.org/10.5751/ES-07469-200167

McAllister, R. R. J., and B. M. Taylor. 2015. Partnerships for sustainability governance: a synthesis of key themes. Current Opinion in Environmental Sustainability 12:86-90. http://dx.doi. org/10.1016/j.cosust.2015.01.001

Meek, C. L. 2013. Forms of collaboration and social fit in wildlife management: a comparison of policy networks in Alaska. Global Environmental Change 23:217-228. http://dx.doi.org/10.1016/j. gloenvcha.2012.10.003

Morrison, T. H. 2007. Multiscalar governance and regional environmental management in Australia. Space and Polity 11:227-241. http://dx.doi.org/10.1080/13562570701811551

Munck af Rosenschöld, J., N. Honkela, and J. I. Hukkinen. 2014. Addressing the temporal fit of institutions: the regulation of endocrine-disrupting chemicals in Europe. Ecology and Society 19(4):30. http://dx.doi.org/10.5751/ES-07033-190430

Nagendra, H., and E. Ostrom. 2012. Polycentric governance of multifunctional forested landscapes. International Journal of the Commons 6:104-133. http://dx.doi.org/10.18352/ijc.321

Newig, J., and O. Fritsch. 2009. Environmental governance: participatory, multi-level-and effective? Environmental Policy and Governance 19:197-214. http://dx.doi.org/10.1002/eet.509
O'Keefe, C. E., and G. R. DeCelles. 2013. Forming a partnership to avoid bycatch. Fisheries 38:434-444. http://dx.doi. org/10.1080/03632415.2013.838122

Olsson, P., C. Folke, V. Galaz, T. Hahn, and L. Schultz. 2007. Enhancing the fit through adaptive co-management: creating and maintaining bridging functions for matching scales in the Kristianstads Vattenrike Biosphere Reserve, Sweden. Ecology and Society 12(1):28. [online] URL: http://www.ecologyandsociety. org/vol12/iss $1 / \operatorname{art} 28 /$

ÖSterblom, H., and Ö. Bodin. 2012. Global cooperation among diverse organizations to reduce illegal fishing in the Southern Ocean. Conservation Biology 26:638-648. http://dx.doi. org/10.1111/j.1523-1739.2012.01850.x

Ostrom, E. 1990. Governing the commons: the evolution of institutions for collective action. Cambridge University Press, Cambridge, UK. http://dx.doi.org/10.1017/CBO9780511807763

Ostrom, E. 2010a. Polycentric systems for coping with collective action and global environmental change. Global Environmental Change 20:550-557. http://dx.doi.org/10.1016/j.gloenvcha.2010.07.004

Ostrom, E. 2010b. A long polycentric journey. Annual Review of Political Science 13:1-23. http://dx.doi.org/10.1146/annurev. polisci.090808.123259

Ostrom, E., J. Burger, C. B. Field, R. B. Norgaard, and D. Policansky. 1999. Revisiting the commons: local lessons, global challenges. Science 284:278-282. http://dx.doi.org/10.1126/ science.284.5412.278

Pahl-Wostl, C. 2009. A conceptual framework for analysing adaptive capacity and multi-level learning processes in resource governance regimes. Global Environmental Change 19:354-365. http://dx.doi.org/10.1016/j.gloenvcha.2009.06.001

Pelosi, C., M. Goulard, and G. Balent. 2010. The spatial scale mismatch between ecological processes and agricultural management: do difficulties come from underlying theoretical frameworks? Agriculture Ecosystems \& Environment 139:455-462. http://dx.doi.org/10.1016/j.agee.2010.09.004

Poiani, K. A., B. D. Richter, M. G. Anderson, and H. E. Richter. 2000. Biodiversity conservation at multiple scales: functional sites, landscapes, and networks. BioScience 50:133-146. http://dx. doi.org/10.1641/0006-3568(2000)050[0133:BCAMSF]2.3.CO;2

Provan, K. G., and P. Kenis. 2008. Modes of network governance: structure, management, and effectiveness. Journal of Public Administration Research and Theory 18:229-252. http://dx.doi. org/10.1093/jopart/mum015

Runge, C. A., T. G. Martin, H. P. Possingham, S. G. Willis, and R. A. Fuller. 2014. Conserving mobile species. Frontiers in Ecology and the Environment 12:395-402. http://dx.doi. org/10.1890/130237

Sabatier, P. A. 2005. Swimming upstream: collaborative approaches to watershed management. MIT Press, Cambridge, Massachusetts, USA.

Saunders, D. A., and S. V. Briggs. 2002. Nature grows in straight lines - or does she? What are the consequences of the mismatch between human-imposed linear boundaries and ecosystem 
boundaries? An Australian example. Landscape and Urban Planning 61:71-82. http://dx.doi.org/10.1016/S0169-2046(02) 00103-2

Saura, S., and L. Pascual-Hortal. 2007. A new habitat availability index to integrate connectivity in landscape conservation planning: comparison with existing indices and application to a case study. Landscape and Urban Planning 83:91-103. http://dx. doi.org/10.1016/j.landurbplan.2007.03.005

Sayre, N. F. 2005. Ecological and geographical scale: parallels and potential for integration. Progress in Human Geography 29:276-290. http://dx.doi.org/10.1191/0309132505ph546oa

Shackleton, C. M., G. Cundill, and A. T. Knight. 2009. Beyond just research: experiences from Southern Africa in developing social learning partnerships for resource conservation initiatives. Biotropica 41:563-570. http://dx.doi.org/10.1111/j.1744-7429.2009.00559. $\underline{\mathrm{X}}$

Snijders, T. A. B., P. E. Pattison, G. L. Robins, and M. S. Handcock. 2006. New specifications for exponential random graph models. Sociological Methodology 36:99-153. http://dx.doi. org/10.1111/j.1467-9531.2006.00176.X

Sørensen, E., and J. Torfing. 2006. Theories of democratic network governance. Palgrave Macmillan, London, UK. http:// dx.doi.org/10.1057/9780230625006

Sutherland, G. D., A. S. Harestad, K. Price, and K. P. Lertzman. 2000. Scaling of natal dispersal distances in terrestrial birds and mammals. Conservation Ecology 4(1):16. [online] URL: http:// www.consecol.org/vol4/iss 1/art16/

Treml, E. A., P. I. J. Fidelman, S. Kininmonth, J. A. Ekstrom, and Ö. Bodin. 2015. Analyzing the (mis)fit between the institutional and ecological networks of the Indo-West Pacific. Global Environmental Change 31:263-271. http://dx.doi.org/10.1016/j. gloenvcha.2015.01.012

Tulloch, A. I. T., V. J. D. Tulloch, M. C. Evans, and M. Mills. 2014. The value of using feasibility models in systematic conservation planning to predict landholder management uptake. Conservation Biology 28:1462-1473. http://dx.doi.org/10.1111/ $\underline{\text { cobi. } 12403}$

Vatn, A., and P. Vedeld. 2012. Fit, interplay, and scale: a diagnosis. Ecology and Society 17(4):12. http://dx.doi.org/10.5751/ ES-05022-170412

Visseren-Hamakers, I. J., and P. Glasbergen. 2007. Partnerships in forest governance. Global Environmental Change 17:408-419. http://dx.doi.org/10.1016/j.gloenvcha.2006.11.003

Walker, B., S. Barrett, S. Polasky, V. Galaz, C. Folke, G. Engstrom, F. Ackerman, K. Arrow, S. Carpenter, K. Chopra, G. Daily, P. Ehrlich, T. Hughes, N. Kautsky, S. Levin, K.-G. Mäler, J. Shogren, J. Vincent, T. Xepapadeas, and A. de Zeeuw. 2009. Looming global-scale failures and missing institutions. Science 325:1345-1346. http://dx.doi.org/10.1126/science.1175325

Walker, B., C. S. Holling, S. R. Carpenter, and A. Kinzig. 2004. Resilience, adaptability and transformability in social-ecological systems. Ecology and Society 9(2):5. [online] URL: http://www. ecologyandsociety.org/vol9/iss2/art5/
Wang, P., G. Robins, P. Pattison, and E. Lazega. 2013. Exponential random graph models for multilevel networks. Social Networks 35:96-115. http://dx.doi.org/10.1016/j.socnet.2013.01.004

Wasserman, S., and P. Pattison. 1996. Logit models and logistic regressions for social networks. 1. An introduction to Markov graphs and p. Psychometrika 61:401-425. http://dx.doi. org/10.1007/BF02294547

Wiens, J. A. 1989. Spatial scaling in ecology. Functional Ecology 3:385-397. http://dx.doi.org/10.2307/2389612

Wilbanks, T. J., and R. W. Kates. 1999. Global change in local places: how scale matters. Climatic Change 43:601-628. http://dx. doi.org/10.1023/A:1005418924748

Wilson, J. A. 2006. Matching social and ecological systems in complex ocean fisheries. Ecology and Society 11(1):9. [online] URL: http://www.ecologyandsociety.org/vol11/iss1/art9/

Wyborn, C. 2015. Cross-scale linkages in connectivity conservation: adaptive governance challenges in spatially distributed networks. Environmental Policy and Governance 25:1-15. http://dx.doi.org/10.1002/eet.1657

Young, O. R. 2002. The institutional dimensions of environmental change: fit, interplay, and scale. MIT Press, Cambridge, Massachusetts, USA.

Young, O. R., L. A. King, and H. Schroeder, editors. 2008. Institutions and environmental change: principal findings, applications and research frontiers. MIT Press, Cambridge, Massachusetts, USA. http://dx.doi.org/10.7551/mitpress/97802$\underline{62240574.001 .0001}$

Zetterberg, A., U. M. Mörtberg, and B. Balfors. 2010. Making graph theory operational for landscape ecological assessments, planning, and design. Landscape and Urban Planning 95:181-191. http://dx.doi.org/10.1016/j.landurbplan.2010.01.002 


\section{Appendix 1}

Figures A1.1 and A1.2 show the perceptions held by Fitz-Stirling actors on the effects of collaborative relationships on the performance of on-ground activities. Data were gathered through semistructured interviews and a survey conducted online using the software Checkbox. Survey data were collected between October 2011 and July 2012. A copy of the questions can be provided upon request.

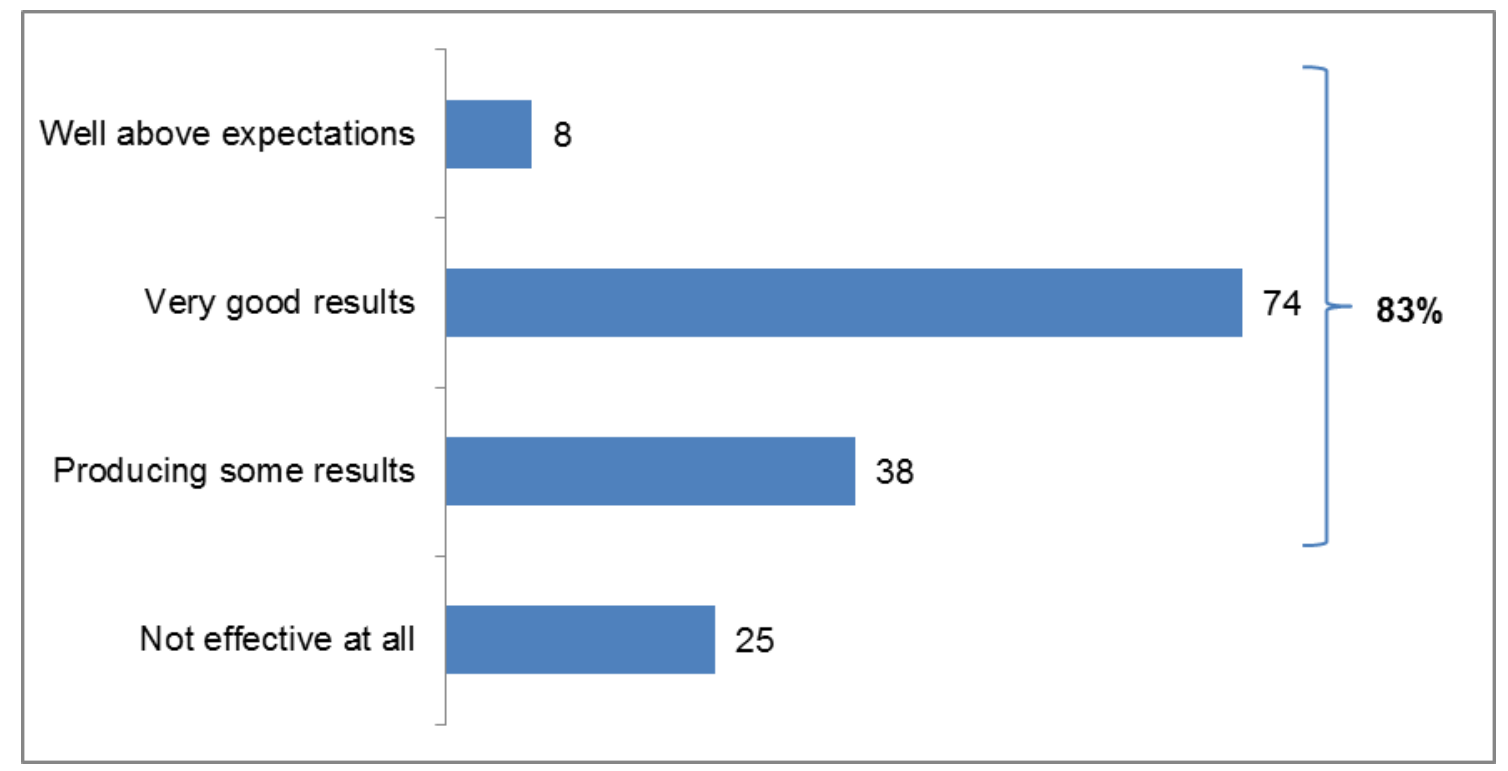

Figure A1.1 Number of collaborations perceived as delivering some, very good, or results above expectations to the particular activity performed at a particular location $\mathrm{n}=145$. 


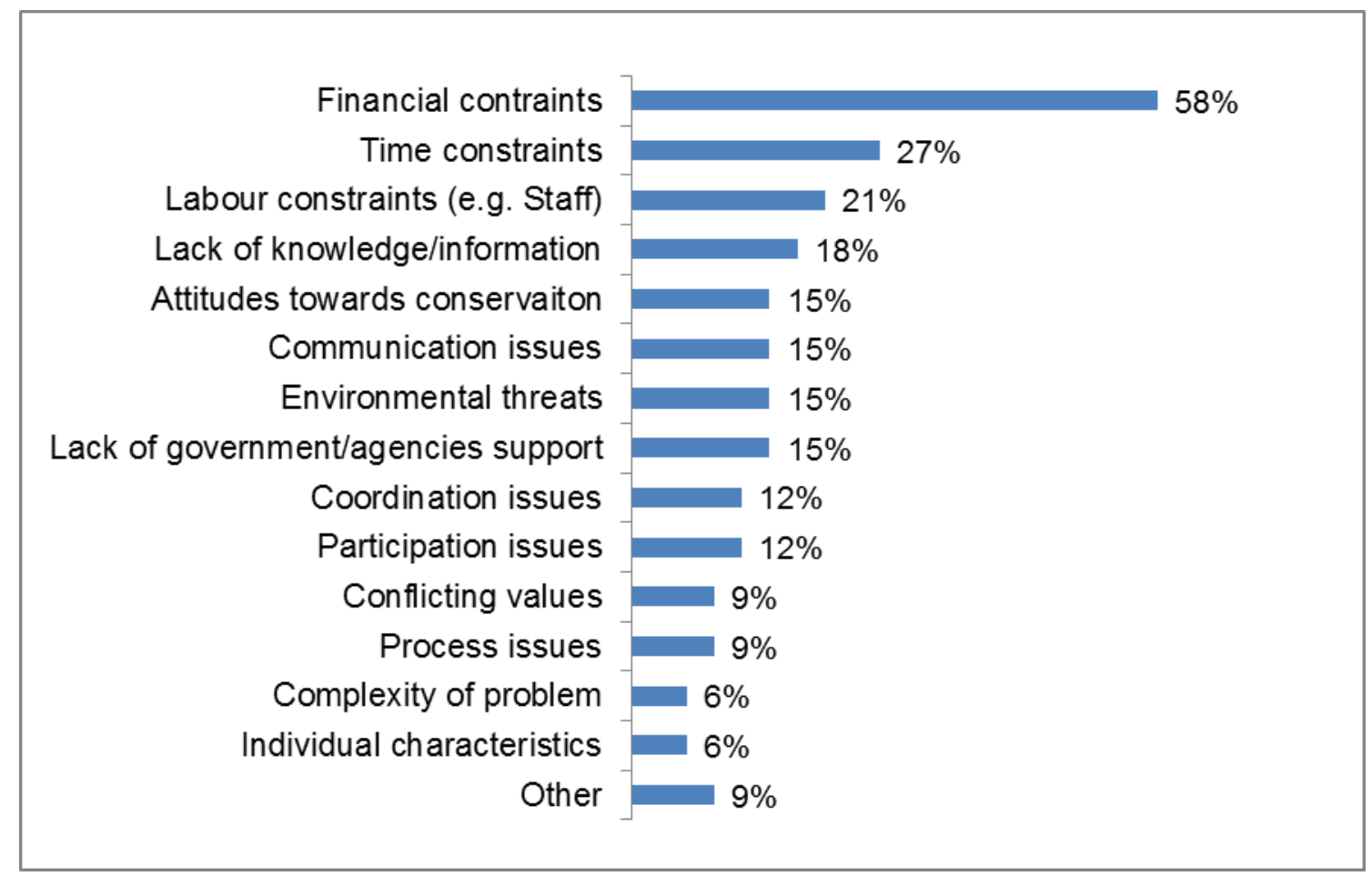

Figure A1.2. Perceived barriers to conservation action implementation including communication and coordination issues. Proportion of respondents who mentioned each barrier - unprompted ( $n=33)$. 